\title{
Racial Background and Health Behaviors Among Adults With Cancer in Canada: Results of a National Survey
}

\author{
Omar Abdel-Rahman, $\mathrm{MD}^{1}$
}

\begin{abstract}
Background: This study was an assessment of the impact of racial background on health behaviors among Canadian adults with a concurrent or past history of a cancer diagnosis. Methods: The Canadian Community Health Survey datasets (2015-2018) were accessed, and adults (age $\geq 18$ years) with cancer were reviewed. Information about the racial background, socioeconomic status, and different health behaviors was reviewed. Multivariable logistic regression analyses for factors associated with different health behaviors were conducted. Results: A total of 20,514 participants with a history of cancer were considered eligible and were included in the analysis. Compared with individuals who self-identified as White, those who self-identified as indigenous were less likely to have received an influenza vaccination in the past year (odds ratio [OR], 1.253; $95 \% \mathrm{Cl}$, 1.084-1.448), less likely to have drunk alcohol in the past 12 months (OR, 0.641; 95\% Cl, 0.546-0.752), more likely to be current smokers (OR, 2.245; 95\% Cl, 1.917-2.630), and more likely to have used recreational drugs in the past 12 years $(\mathrm{OR}, 1.488 ; 95 \% \mathrm{Cl}, 1.076-2.057)$. Compared with individuals who self-identified as White, those who self-identified as non-White and nonindigenous were less likely to have received an influenza vaccination in the past year (OR, 1.207; $95 \% \mathrm{Cl}, 1.035-1.408)$, less likely to have drunk alcohol in the past 12 months (OR, 0.557; $95 \% \mathrm{Cl}, 0.463-0.671)$, and less likely to be current smokers (OR, $0.605 ; 95 \% \mathrm{Cl}, 0.476-0.769)$. Conclusions: Within the Canadian context, there is a considerable variability in the health behaviors of adults with cancer according to their racial background. There is a need to tailor the survivorship care planning of patients with cancer based on socioeconomic context.
\end{abstract}

J Natl Compr Canc Netw, doi: 10.6004/jnccn.2020.7681 Published online June 17, 2021

${ }^{1}$ Department of Oncology, University of Alberta and Cross Cancer Institute, Edmonton, Alberta, Canada.

\section{Background}

Patients with cancer and cancer survivors are generally advised to observe healthy behaviors during and after the end of cancer treatment. ${ }^{1}$ These include maintaining recommended vaccinations (eg, influenza vaccination), maintaining physical activity, limiting consumption of alcohol, and abstinence from cigarette smoking and illicit drug use. ${ }^{2-5}$ Previous studies have linked these healthy behaviors with favorable long-term outcomes. ${ }^{6,7}$ Although previous studies have assessed patterns of health behavior among Canadian adults with cancer, assessment of the impact of racial background and socioeconomic factors on these health behaviors in a national context was not available. ${ }^{8}$ Such an assessment is important to guide health authorities and practitioners to provide a personalized cancer survivorship message (according to individual characteristics) instead of the currently available generic messages and advice that do not take into consideration the variable prevalence of different behaviors in different sectors of society. ${ }^{1,9-13}$

The Canadian Community Health Survey (CCHS) is a national survey that has been conducted regularly on an annual basis. ${ }^{14}$ It provides population-level data on health status, social determinants of health, and health resource use within a representative sample of the Canadian population. Therefore, it offers an ideal context to study health behaviors and patterns among different subgroups of the population, and thus should help tailor the public health message to the needs of the public. The main hypothesis of the present study is that health behavior patterns differ according to socioeconomic status (SES) and racial background, and the objective of this study is to assess the impact of racial background on health behaviors among Canadian adults with a current or past history of a cancer diagnosis.

\section{Methods}

\section{CCHS Scope and Potential}

CCHS is an annual cross-sectional survey that provides information about health conditions, attitudes, and behaviors

See JNCCN.org for supplemental online content. 
of Canadians aged $>12$ years. Almost $97 \%$ of the Canadian population is represented within CCHS datasets; those who are not represented include some individuals living in indigenous settlements, Canadian Forces full-time members, some Quebec health regions, and institutionalized people. A sampling of participants was conducted through area framing (using Statistics Canada's Labour Force Survey sampling frame), list framing (using the Canadian phone directory), and supplementation with random dialing in some health regions. Data collection and interviews were conducted through personal and telephone-based interviews. Full details about the methodology used in CCHS sampling were provided in its published documentation. ${ }^{14}$ The CCHS response rate from 2015 to 2016 was 59.5\%, and in 2018 was $58.8 \%$.

\section{Cohort Selection}

The present study is based on CCHS cohorts (20152018). The reason for selecting these years is that before the 2015-2016 dataset release, the aboriginal (indigenous) identity variable was not released in the CCHS public use microdata files. Statistics Canada allowed the release of aboriginal (indigenous) identity variables starting from 2015.

The following selection criteria were used for this study cohort: adult (aged $>18$ years) residents of Canada who were included in the respective CCHS datasets and had a history of a cancer diagnosis. CCHS datasets contain 2 questions related to cancer history. The first question is, "Do you have cancer?" If the participant answers "no," then they are asked, "Have you ever been diagnosed with cancer?" Based on the answers to both of these questions, CCHS participants were classified into those with a current cancer diagnosis and those with a history of cancer (survivors); those without a history of cancer were excluded.

\section{Data Collection}

The following data were collected from each included participant when available: age at survey completion, racial background (White, indigenous, or non-White and nonindigenous), sex, cancer history, total household income in Canadian dollars $(<\$ 20,000, \$ 20,000$ to $<\$ 40,000, \$ 40,000$ to $<\$ 60,000, \$ 60,000$ to $<\$ 80,000, \geq \$ 80,000$ ), province/ territory of residence at the time of survey completion, self-perceived health, self-perceived mental health, and marital status. Among individuals identifying as nonWhite and nonindigenous, the following information was collected: knowledge of official languages (English and/or French), place of birth, and length of time in Canada since immigration (if applicable). Further description of the racial background of this group (eg, Black or Asian) was not provided within CCHS datasets.
The following data were also collected: history of influenza vaccination (flu shot) in the past year, physical activity level (at/more than vs less than recommended level according to Canadian Physical Activity Guidelines), ${ }^{15}$ current smoking status (daily, occasionally, or not at all), alcohol consumption in the past 12 months (yes or no), and recreational drug use (including marijuana) in the past 12 months (yes or no). It must be noted that recreational drug use was reported in CCHS datasets as "illicit drug use," but because this category includes marijuana use (which was legalized in Canada in 2018), the term "recreational drug use" was used in the present study. Current smokers were defined as those who reported being current daily or occasional smokers.

\section{Statistical Analysis}

Chi-square testing was initially performed to compare baseline categorical variables and ANOVA test was performed to compare continuous variables among the 3 racial groups. Weighted frequencies for categorical variables were also examined after taking into consideration the sample weights provided by each CCHS dataset.

Multivariable logistic regression analyses were then conducted to assess the factors affecting each of the following: influenza vaccination, physical activity, alcohol consumption, cigarette smoking, and recreational drug use. It must be noted that the population used in each of these models was limited to individuals with complete information about the respective endpoint. Each of these models was adjusted for age, racial background, sex, marital status, income level, self-perceived health, selfperceived mental health, and cancer status (current cancer diagnosis vs cancer history). These variables were chosen because of their proven relevance to health behaviors and outcomes among patients with cancer. All statistical analyses were conducted using SPSS Statistics, version 26.0 (IBM Corp.), except for weighted frequencies, which were performed using STATA, version 14.0 (StataCorp LLP).

\section{Results}

\section{Participant Characteristics}

A total of 20,514 participants with a history of cancer were found to be eligible for the present study, including 18,799 participants who self-identified as White, 896 who self-identified as indigenous, and 819 who self-identified as non-White and nonindigenous. Compared with participants who self-identified as White, those who self-identified as indigenous were more likely to have younger age, female sex, poorer self-perceived health, poorer self-perceived mental health, lower household income, less alcohol consumption in the past 12 months, fewer average weekly alcoholic drinks, higher rates of cigarette smoking, higher 
rates of illicit drug use, and lower rates of influenza vaccination in the past 12 months $(P<.001$ for all), but no difference in physical activity $(P=.463)$. Compared with participants who self-identified as White, those who selfidentified as non-White and nonindigenous were more likely to have younger age, married status, poorer selfperceived health, poorer self-perceived mental health, less alcohol consumption in the past 12 months, lower rates of cigarette smoking, and lower rates of influenza vaccination in the past 12 months $(P<.001$ for all) (Table 1). Similar findings were observed in the weighted frequency analysis (supplemental eTable 1, available with this article at JNCCN.org), except for higher rates of physical activity among participants who self-identified as indigenous versus those who self-identified as White or as non-White and nonindigenous $(P<.001)$. Among participants who self-identified as non-White and nonindigenous, 7.5\% knew neither English nor French, 75.4\% were born outside Canada, and 9.3\% had been in Canada for $<10$ years. Health behaviors in each of the 3 racial groups within different Canadian provinces are detailed in Figure 1.

Impact of Racial Background on Different Health Behaviors

\section{Influenza Vaccination}

The following factors were associated with less probability of influenza vaccination: non-White racial background (odds ratio $[\mathrm{OR}]$ for indigenous vs White, 1.253; 95\% CI, 1.084-1.448; OR for non-White and nonindigenous vs White, 1.207; 95\% CI, 1.035-1.408), younger age (OR, 2.043; 95\% CI, 1.737-2.403), male sex (OR, 1.139; 95\% CI, 1.070-1.212), married status (OR vs unmarried status, 0.864; 95\% CI, 0.809-0.924), better self-perceived health (OR, 1.626; 95\% CI, 1.402-1.885), and lower income (OR for higher vs lower income, $0.715 ; 95 \% \mathrm{CI}$, 0.638-0.801) (Table 2).

\section{Physical Activity}

The following factors were associated with having less than the recommended level of physical activity: older age (OR, 2.103; 95\% CI, 1.973-2.242), female sex (OR for male vs female, 0.743 ; $95 \% \mathrm{CI}, 0.698-0.792$ ), poor self-perceived health (OR, 0.244; 95\% CI, 0.208-0.285), and lower income (OR for higher vs lower income, 0.628; 95\% CI, 0.560-0.705). There was no difference between participants self-identifying as indigenous and those self-identifying as White with regard to physical activity (OR, 0.913; 95\% CI, 0.788-1.058). Likewise, there was no difference between participants self-identifying as non-White and nonindigenous and those self-identifying as White (OR, 1.056; 95\% CI, 0.903-1.235).

\section{Alcohol Consumption}

The following factors were associated with alcohol consumption in the past 12 months: White racial background (OR for indigenous vs White background, 0.641; 95\% CI, 0.546-0.752; OR for non-White and nonindigenous vs White, $0.557 ; 95 \% \mathrm{CI}, 0.463-0.671)$, younger age (OR, 2.132; 95\% CI, 1.659-2.742), male sex (OR, 1.182; 95\% CI, 1.095-1.277), better self-perceived health (OR, 3.171; 95\% CI, 2.651-3.792), and higher income (OR, 2.659; 95\% CI, 2.326-3.039).

\section{Current Cigarette Smoking}

The following factors were associated with current smoking (at the time of survey completion): indigenous racial background (OR, 2.245; 95\% CI, 1.917-2.630), younger age (OR, 1.652; 95\% CI, 1.394-1.958), unmarried status (OR for married vs unmarried, $0.548 ; 95 \%$ CI, $0.497-0.604$ ), poor self-perceived health (OR for excellent vs poor perceived health, 0.376; 95\% CI, 0.307-0.462), poor self-perceived mental health (OR for excellent vs poor perceived mental health, 0.584; 95\% CI, 0.454-0.751), lower income (OR for income $\geq \$ 80,000$ vs $<\$ 20,000,0.426 ; 95 \% \mathrm{CI}$, 0.369-0.491), and a history of cancer (OR for current cancer diagnosis vs history of cancer, $0.858 ; 95 \% \mathrm{CI}$, 0.771-0.956). However, participants who self-identified as non-White and nonindigenous were less likely than White participants to be current smokers (OR, 0.605; 95\% CI, 0.476-0.769).

\section{Recreational Drug Use}

The following factors were associated with recreational drug use in the past 12 months: indigenous racial background (OR, 1.488; 95\% CI, 1.076-2.057), younger age (OR, 3.488; 95\% CI, 2.618-4.646), male sex (OR, 1.925; 95\% CI, 1.601-2.315), unmarried status (OR for married vs unmarried, 0.519 ; 95\% CI, 0.421-0.640), poor self-perceived health (OR for excellent vs poor perceived health, 0.626 ; $95 \%$ CI, 0.407-0.961), poor self-perceived mental health (OR for excellent vs poor perceived mental health, 0.255 ; 95\% CI, 0.163-0.397), and lower income (OR for income $\geq \$ 80,000$ vs $<\$ 20,000,0.731 ; 95 \%$ CI, $0.541-0.987)$. However, no difference was observed between participants who were non-White and nonindigenous and participants who were White with regard to recreational drug use in the past 12 months (OR, 0.718; 95\% CI, $0.452-1.139$ ).

\section{Discussion}

To the best of knowledge, this is the largest and most upto-date study to assess the impact of racial background on health behaviors among Canadian adults with a cancer history. Compared with individuals who self-identify as White, those who self-identify as indigenous were more likely to be current smokers and report recreational 


\begin{tabular}{|c|c|c|c|c|}
\hline Variable $^{a}$ & $\begin{array}{l}\text { White } \\
\text { n (\%) }\end{array}$ & $\begin{array}{c}\text { Indigenous } \\
\text { n (\%) }\end{array}$ & $\begin{array}{c}\text { Non-White/ } \\
\text { Nonindigenous } \\
\text { n (\%) }\end{array}$ & $P$ Value \\
\hline Total, N & 18,799 & 896 & 819 & \\
\hline Age & & & & $<.001$ \\
\hline $18-39 y$ & $644(3.4)$ & $88(9.8)$ & $58(7.1)$ & \\
\hline $40-69 y$ & $9,085(48.3)$ & $554(61.8)$ & $453(55.3)$ & \\
\hline$\geq 70 y$ & $9,070(48.2)$ & $254(28.3)$ & $308(37.6)$ & \\
\hline Sex & & & & $<.001$ \\
\hline Male & $7,707(41)$ & $309(34.5)$ & $324(39.6)$ & \\
\hline Female & $11,092(59)$ & $587(65.5)$ & $495(60.4)$ & \\
\hline Marital status & & & & $<.001$ \\
\hline Married & $8,950(47.6)$ & $315(35.2)$ & $443(54.1)$ & \\
\hline Unmarried & $9,798(52.1)$ & $577(64.4)$ & $373(45.5)$ & \\
\hline Unknown & $51(0.3)$ & $4(0.4)$ & $3(0.4)$ & \\
\hline Self-perceived health & & & & $<.001$ \\
\hline Excellent & $2,127(11.4)$ & $61(6.9)$ & $77(9.4)$ & \\
\hline Very good & $5,322(28.4)$ & $159(17.9)$ & $163(20)$ & \\
\hline Good & $6,195(33.1)$ & $309(34.7)$ & $312(38.2)$ & \\
\hline Fair & $3,376(18)$ & $226(25.4)$ & $162(19.9)$ & \\
\hline Poor & $1,718(9.2)$ & $102(12.5)$ & $102(12.5)$ & \\
\hline Self-perceived mental health & & & & $<.001$ \\
\hline Excellent & $5,411(30.3)$ & $199(23)$ & $202(26.9)$ & \\
\hline Very good & $6,353(35.6)$ & $254(29.3)$ & $238(31.6)$ & \\
\hline Good & $4,552(25.5)$ & $264(30.4)$ & $218(29)$ & \\
\hline Fair & $1,212(6.8)$ & $110(12.7)$ & $73(9.7)$ & \\
\hline Poor & 319 (1.9) & $40(4.6)$ & $21(2.9)$ & \\
\hline Total household income (CAD\$) & & & & $<.001$ \\
\hline$<\$ 20,000$ & $1,997(10.6)$ & $200(22.4)$ & $111(13.6)$ & \\
\hline$\$ 20,000$ to $<\$ 40,000$ & $4,636(24.7)$ & $224(25.1)$ & $190(23.2)$ & \\
\hline$\$ 40,000$ to $<\$ 60,000$ & $3,620(19.3)$ & $148(16.6)$ & $123(15)$ & \\
\hline$\$ 60,000$ to $<\$ 80,000$ & $2,629(14)$ & $105(11.8)$ & $107(13.1)$ & \\
\hline$\geq \$ 80,000$ & $5,904(31.4)$ & $215(24.1)$ & $288(35.2)$ & \\
\hline
\end{tabular}

(continued on next page)

drug use. They were also less likely to have consumed alcohol in the past year and to have received a timely influenza vaccination. However, compared with individuals who self-identify as White, those who self-identify as non-White and nonindigenous were less likely to have received a timely influenza vaccination, to be current smokers, or to have consumed alcohol in the past year. Further work is needed to improve awareness among patients with cancer of different backgrounds regarding the importance of healthy behaviors and to minimize the disparity in access to supportive services.

It is important to note that a number of factors might have contributed to the observed differences in health behaviors. Within this study cohort, individuals with indigenous racial background were younger in age, which could have partly contributed to a higher probability of cigarette smoking and illicit drug use. Moreover, this can explain a higher probability of achieving recommended physical activity levels in the weighted frequency analysis. Likewise, the differences in income between participants of different racial backgrounds likely affected the observed differences in health behaviors. There could also be an element of geographic disparity interacting with racial disparities. For example, individuals living in remote areas within different jurisdictions would be less likely than those living in metropolitan areas of the same jurisdiction to access different aspects of preventive/survivorship care. It was not 


\begin{tabular}{|c|c|c|c|c|}
\hline Alcohol consumption in past $12 \mathrm{mo}$ & & & & $<.001$ \\
\hline Yes & $14,036(77.9)$ & $592(68.2)$ & $449(68.3)$ & \\
\hline No & $3,986(22.1)$ & $276(31.8)$ & $208(31.7)$ & \\
\hline Type of smoker (cigarette) & & & & $<.001$ \\
\hline Daily & $2,196(11.7)$ & $266(29.7)$ & $61(7.5)$ & \\
\hline Occasional & $493(2.6)$ & $60(6.7)$ & $28(3.4)$ & \\
\hline Not at all & $16,100(85.7)$ & $569(63.6)$ & $729(89.1)$ & \\
\hline Recreational drug use ${ }^{c}$ in the past $12 \mathrm{mo}$ & & & & $<.001$ \\
\hline Within $1 \mathrm{y}$ & $10,401(55.3)$ & $403(46.4)$ & $384(51.3)$ & \\
\hline Not received or received $>1$ y ago & $7,448(41.7)$ & $466(63.6)$ & $365(48.7)$ & \\
\hline Physical activity (as per CPAG) & & & & .463 \\
\hline At/More than recommended & $8,040(43.8)$ & $399(45.5)$ & $341(42.6)$ & \\
\hline Less than recommended/no exercise & $10,327(56.2)$ & $477(54.5)$ & $459(57.4)$ & \\
\hline Self-reported cancer status ${ }^{d}$ & & & & $<.001$ \\
\hline Current cancer diagnosis & $3,943(21)$ & $177(19.8)$ & $230(28.1)$ & \\
\hline History of cancer & $14,856(79)$ & $719(80.2)$ & $589(71.9)$ & \\
\hline
\end{tabular}

Abbreviation: CPAG, Canadian Physical Activity Guidelines.

${ }^{a}$ Missing data: perceived health, $\mathrm{n}=70$; perceived mental health, $\mathrm{n}=1,048$; alcohol consumption, $\mathrm{n}=967$; total household income, $\mathrm{n}=17$; recreational drugs, $n=11,945$; type of smoker, $n=12$; influenza vaccination, $n=1,047$; physical activity, $n=471$.

bIncludes the 3 groups described as aboriginal within the Canadian Community Health Survey datasets: First Nations, Inuit, and Métis.

'Including marijuana.

${ }^{\mathrm{d} D e p e n d s}$ on the type of responses patients provide in the survey.

possible to adjust for this factor in the present analysis. It is notable also that cancer status (current diagnosis vs history) seems to have an impact only on current smoking pattern (cancer survivors were more likely than current patients with cancer to be current smokers).

Previously published studies from several Canadian jurisdictions clarified the particular challenges faced by patients with cancer with an indigenous racial background. ${ }^{16-18}$ However, the present study is unique in its up-to-date data collection and the comprehensive national overview it provides; previous studies focused on one Canadian province only. The current study also highlights the association between low SES, specifically income, and some unhealthy behaviors among adults with cancer. These results are in line with previously published data in Canada and other parts of the world. This is also in line with other publications highlighting the association between low SES and poor cancer-specific outcomes across many solid tumors. ${ }^{19-22}$ Similar disparities in health behaviors have also been noted in the general population in Canada. ${ }^{23}$
The current study has suggested that almost $50 \%$ of adults with cancer in Canada did not receive influenza vaccination in the past year up to survey completion. This is consistent with a number of population-based studies in North America and elsewhere suggesting the challenges associated with adherence to recommended vaccination among patients with cancer. ${ }^{24-27}$ There is a need for focused awareness campaigns and involvement of different healthcare providers to ensure better adherence rates among patients with cancer. The current study also showed that $>50 \%$ of participants did not fulfill Canadian Physical Activity Guidelines recommendations for physical activity. This is concerning, given prior attributes of $>3,000$ cancer cases in Canada to leisure-time sedentary behavior in $2015 .^{28}$ Further work is needed to improve the awareness of adults with cancer about the importance of maintaining physical activity.

The present study has many limitations that are important and relevant to discuss. First, racial background is based on self-identification by participants. A previous study from the United States suggested an $11 \%$ 


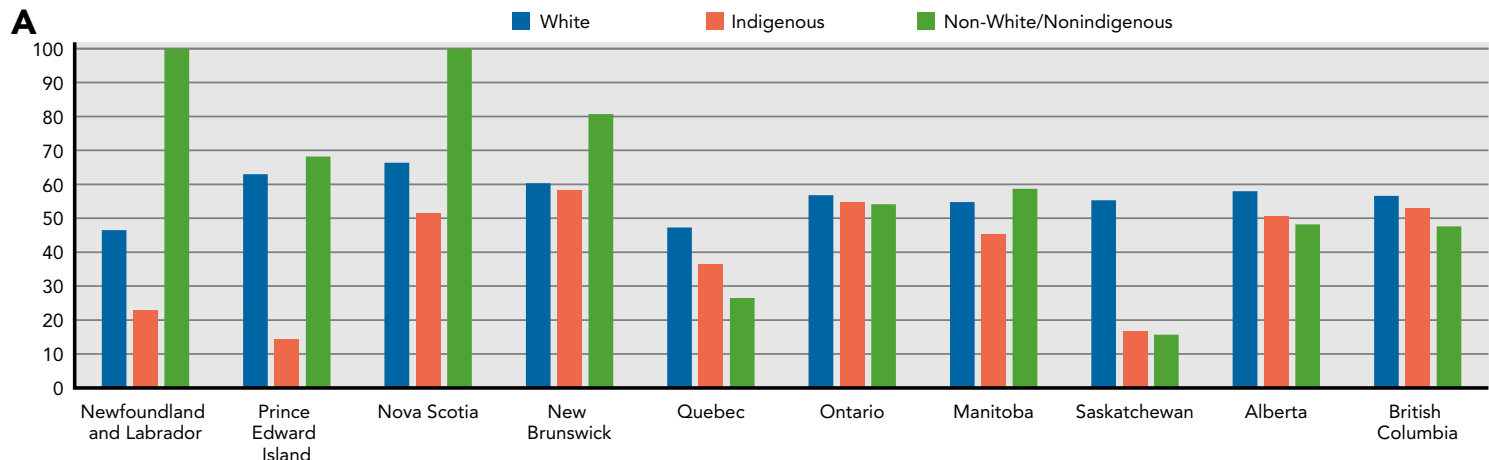

B

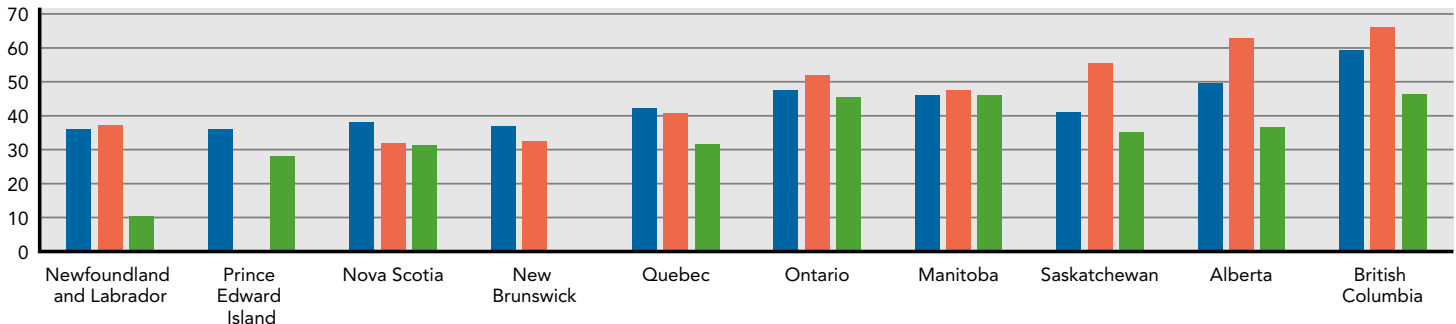

C

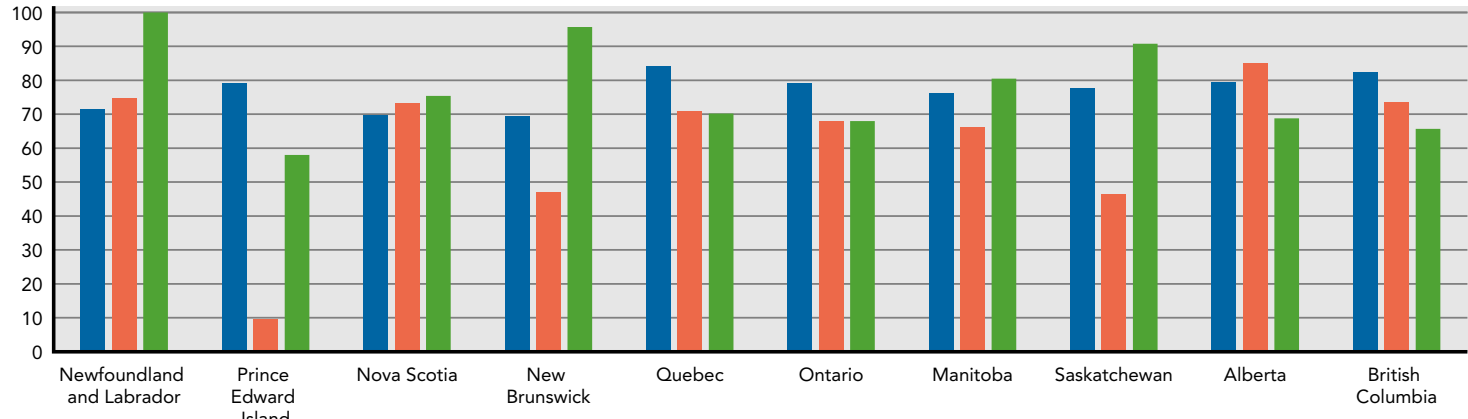

D

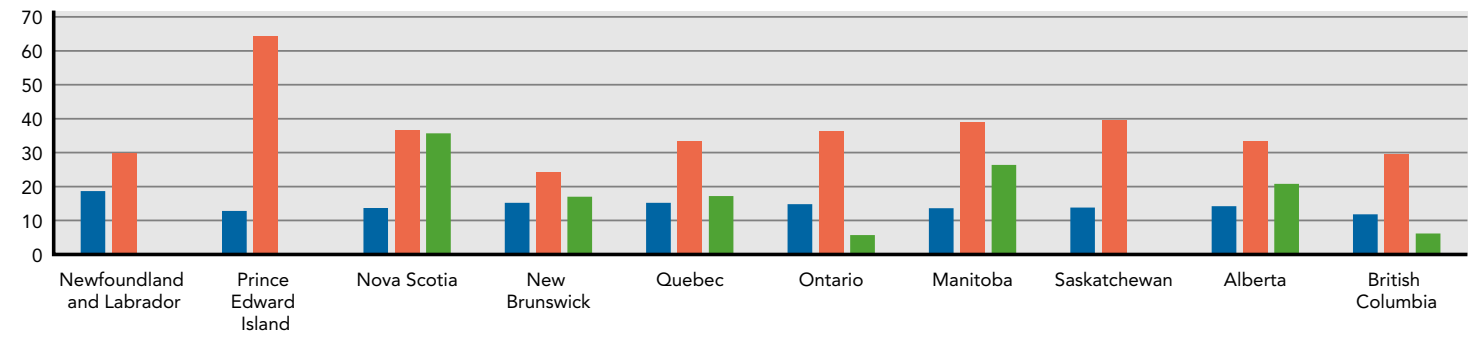

$\mathbf{E}$

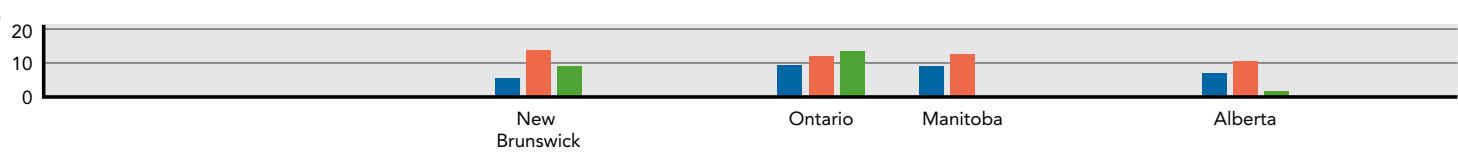

Figure 1. Weighted distribution of different health behaviors according to racial background. Rates of (A) having influenza vaccination within 1 year of survey completion, (B) having recommended/above-recommended exercise level, (C) alcohol consumption, (D) current smokers, and (E) recreational drug use ${ }^{a}$. Caution is needed when interpreting the results of these charts because of the small numbers of participants in each subgroup. The Yukon Territory, the Northwest Territories, and Nunavut are not represented in these figures because very small numbers of participants from these jurisdictions were included.

alnformation for provinces not shown was not available.

discordance rate between race within a cancer registry and self-reported race. ${ }^{29}$ Likewise, the diagnosis of cancer itself is based on self-reporting by participants. A previous Australian study cast some doubt on the validity of self-reported information in colorectal cancer diagnosis. ${ }^{30}$ This is a potential source of bias related to 


\begin{tabular}{|c|c|c|c|c|c|}
\hline \multicolumn{6}{|l|}{ Racial group } \\
\hline White & Ref & Ref & Ref & Ref & Ref \\
\hline Non-White/Nonindigenous & $1.207(1.035-1.408)$ & $1.056(0.903-1.235)$ & $0.557(0.463-0.671)$ & $0.605(0.476-0.769)$ & $0.718(0.452-1.139)$ \\
\hline \multicolumn{6}{|l|}{ Age } \\
\hline $40-69 y$ & Ref & Ref & Ref & Ref & Ref \\
\hline $18-39 y$ & $2.043(1.737-2.403)$ & $0.582(0.495-0.683)$ & $2.132(1.659-2.742)$ & $1.652(1.394-1.958)$ & $3.488(2.618-4.646)$ \\
\hline$\geq 70 y$ & $0.342(0.321-0.365)$ & $2.103(1.973-2.242)$ & $0.586(0.543-0.633)$ & $0.275(0.249-0.304)$ & $0.154(0.118-0.201)$ \\
\hline \multicolumn{6}{|l|}{ Sex } \\
\hline \multicolumn{6}{|l|}{ Marital status } \\
\hline Unmarried & Ref & Ref & Ref & Ref & Ref \\
\hline Married & $0.864(0.809-0.924)$ & $0.980(0.917-1.048)$ & $0.994(0.916-1.079)$ & $0.548(0.497-0.604)$ & $0.519(0.421-0.640)$ \\
\hline \multicolumn{6}{|l|}{ Self-perceived health } \\
\hline Poor & Ref & Ref & Ref & Ref & Ref \\
\hline Excellent & $1.626(1.402-1.885)$ & $0.244(0.208-0.285)$ & $3.171(2.651-3.792)$ & $0.376(0.307-0.462)$ & $0.626(0.407-0.961)$ \\
\hline Very good & $1.334(1.173-1.518)$ & $0.316(0.275-0.363)$ & $2.623(2.273-3.027)$ & $0.460(0.391-0.541)$ & $0.660(0.469-0.928)$ \\
\hline Good & $1.184(1.047-1.338)$ & $0.445(0.390-0.508)$ & 2.047 (1.796-2.334) & $0.609(0.526-0.705)$ & $0.713(0.523-0.972)$ \\
\hline Fair & $1.019(0.896-1.158)$ & $0.663(0.577-0.761)$ & $1.338(1.170-1.529)$ & $0.786(0.677-0.912)$ & $0.951(0.699-1.293)$ \\
\hline \multicolumn{6}{|l|}{ Total household income (CAD\$) } \\
\hline$<\$ 20,000$ & Ref & Ref & Ref & Ref & Ref \\
\hline$\$ 20,000$ to $<\$ 40,000$ & $0.869(0.804-0.998)$ & $1.030(0.920-1.153)$ & $1.230(1.095-1.382)$ & $0.719(0.632-0.818)$ & $0.616(0.452-0.839)$ \\
\hline$\$ 40,000$ to $<\$ 60,000$ & $0.766(0.682-0.860)$ & $0.844(0.750-0.951)$ & $1.702(1.495-1.937)$ & $0.554(0.480-0.639)$ & $0.840(0.611-1.154)$ \\
\hline$\$ 60,000$ to $<\$ 80,000$ & $0.713(0.629-0.808)$ & $0.745(0.657-0.846)$ & $1.990(1.720-2.301)$ & $0.514(0.437-0.603)$ & $0.935(0.669-1.307)$ \\
\hline$\geq \$ 80,000$ & $0.715(0.638-0.801)$ & $0.628(0.560-0.705)$ & $2.659(2.326-3.039)$ & $0.426(0.369-0.491)$ & $0.731(0.541-0.987)$ \\
\hline \multicolumn{6}{|l|}{ Self-reported cancer status } \\
\hline History of cancer & Ref & Ref & Ref & Ref & Ref \\
\hline Current cancer diagnosis & $0.931(0.862-1.006)$ & $1.063(0.983-1.149)$ & $1.066(0.973-1.168)$ & $0.858(0.771-0.956)$ & $1.072(0.857-1.341)$ \\
\hline
\end{tabular}

Abbreviation: OR, odds ratio.

alncluding marijuana.

the misrepresentation of individuals' racial background and/or their cancer diagnosis/status. Second, information about cancer type, cancer stage, age at diagnosis, or treatment is not available within the CCHS. Although the 2 questions related to cancer status within the CCHS were used as surrogates for cancer history, they are still crude surrogates because this was not confirmed by objective recording in medical records. Moreover, time since cancer diagnosis is not available. Third, the cohort seems to be skewed toward individuals with White selfidentified racial background; people self-identifying as being White represented $91.6 \%$ of the study population 
(unweighted frequencies), whereas they represented only $73 \%$ of the Canadian population in the 2016 census. ${ }^{31} \mathrm{Al}-$ though reasons for this disproportionate representation are unclear in the CCHS documentation, the fact that some individuals living in indigenous settlements were not represented in the CCHS datasets may have affected the overall representation of different racial groups. Frequency analyses incorporating study weights were added to this study to improve the representativeness of the results (although, as suggested previously, when pooling weights from multiple survey cycles, the resulting weights do represent an average population that does not exist). ${ }^{32}$ Fourth, CCHS datasets focus on the health behaviors of participants but do not comment on health outcomes. Thus, it is not possible to understand how these variable health behavior patterns have affected cancer-specific outcomes in the study population. Fifth, the 3 mentioned racial groups in the present study (White, indigenous, and others) are not, in themselves, homogeneous groups. Within each racial group, there is a possibility of many subgroups that might differ in their health behaviors. Sixth, SES was measured in this study through assessment of total household income. It has been suggested previously that a more comprehensive approach incorporating other dimensions of SES would be more accurate. ${ }^{33,34}$

Overall, these limitations suggest that the results of the present analysis do indicate association rather causation, and further work is needed to confirm these results. These limitations need to be reviewed against the strengths of the present study, including its relatively big sample size, and the contemporaneous nature of data collection.

Current awareness and support programs for patients with cancer and cancer survivors in Canada generally follow a "one size fits all" paradigm, whereby similar advice is provided to adults with cancer regardless of their socioeconomic and cultural background. The present study indicates that such a generic approach is not appropriate, and it is important to retailor support services to better match the needs and challenges faced by different subgroups of society. Cultural competency training also needs to be part of the training process of healthcare providers caring for patients with cancer, and cancer therapy navigators can play an important role in bridging the gaps between providers and patients. ${ }^{35}$ It has been suggested previously that survivorship care plans would improve the outcomes of cancer survivors. ${ }^{36}$

\section{Conclusions}

Within the Canadian context, there is considerable variability in the health behaviors of adults with cancer according to their racial background. Further work is needed to improve awareness among patients with cancer from different backgrounds regarding the importance of healthy behaviors, and to minimize the disparity in access to supportive services.

Submitted July 22, 2020; accepted for publication October 27, 2020. Published online June 17, 2021

Disclosures: Dr. Abdel-Rahman has disclosed serving on an advisory board for Eisai Co., Ltd.

Disclaimer: This study complied with ethical standards. This work is based on the Canadian Community Health Survey (CCHS), which is a Canadian national population-based survey. This dataset can be accessed only after receiving relevant approval from Statistics Canada (https://www.statcan.gc.ca/ eng/survey/household/3226). Because this study was based on the publicly available anonymized dataset, ethical approval was not required. (This is in accordance with Article 2.2 of the Tri-Council Policy Statement: https://ethics. gc.ca/eng/tcps2-eptc2_2018_chapter2-chapitre2.html.) The study was performed following the ethical standards laid down in the 1964 Declaration of Helsinki and its later amendments. All included CCHS participants have signed informed consent as dictated by Statistics Canada policies.

Correspondence: Omar Abdel-Rahman, MD, Department of Oncology, University of Alberta and Cross Cancer Institute, 11560 University Avenue, Edmonton, Alberta, Canada T4G 1Z2. Email: omar.abdelsalam@ahs.ca

\section{References}

1. Sanft $T$, Denlinger CS, Armenian $S$, et al. NCCN guidelines insights: survivorship, version 2.2019. J Natl Compr Canc Netw 2019;17:784-794. For the most recent version of these guidelines, visit NCCN.org

2. Paull DE, Updyke GM, Baumann MA, et al. Alcohol abuse predicts progression of disease and death in patients with lung cancer. Ann Thorac Surg 2005;80:1033-1039.

3. Paull DE, Updyke GM, Davis CA, et al. Complications and long-term survival for alcoholic patients with resectable lung cancer. Am J Surg 2004; 188:553-559.

4. Abdel-Rahman $\mathrm{O}$, Cheung WY. Impact of smoking history on the outcomes of women with early-stage breast cancer: a secondary analysis of a randomized study. Med Oncol 2018;35:68.

5. Abdel-Rahman $O$, Helbling $D$, Schöb $O$, et al. Cigarette smoking as a risk factor for the development of and mortality from hepatocellular carcinoma: an updated systematic review of 81 epidemiological studies. J Evid Based Med 2017;10:245-254.

6. Darcey E, Boyle T. Tobacco smoking and survival after a prostate cancer diagnosis: a systematic review and meta-analysis. Cancer Treat Rev 2018;70:30-40.

7. Gilchrist JD, Conroy DE, Sabiston CM. Associations between alcohol consumption and physical activity in breast cancer survivors. J Behav Med 2020;43:166-173.

8. Bilodeau K, Tremblay D, Durand MJ. Gaps and delays in survivorship care in the return-to-work pathway for survivors of breast cancer-a qualitative study. Curr Oncol 2019;26:e414-417.

9. Nekhlyudov L, Wenger N. Institute of medicine recommendations for improving the quality of cancer care: what do they mean for the general internist? J Gen Intern Med 2014;29:1404-1409.

10. Howell D, Hack TF, Oliver TK, et al. Survivorship services for adult cancer populations: a pan-Canadian guideline. Curr Oncol 2011;18:e265-281.

11. Shapiro CL, Jacobsen PB, Henderson T, et al. ReCAP: ASCO core curriculum for cancer survivorship education. J Oncol Pract 2016;12:145.

12. Sisler J, Chaput G, Sussman J, et al. Follow-up after treatment for breast cancer: practical guide to survivorship care for family physicians. Can Fam Physician 2016;62:805-811.

13. Bower JE, Bak K, Berger A, et al. Screening, assessment, and management of fatigue in adult survivors of cancer: an American Society of Clinical Oncology clinical practice guideline adaptation. J Clin Oncol 2014; 32:1840-1850.

14. Statistics Canada. Canadian Community Health Survey - annual component (CCHS). Accessed December 31, 2019. Available at: https://www. statcan.gc.ca/eng/survey/household/3226 
15. Canadian Physical Activity Guidelines. Accessed July 21, 2020. Available at: http://csep.ca/CMFiles/Guidelines/CSEP_PAGuidelines_0-65plus_en. pdf

16. Horrill TC, Linton J, Lavoie JG, et al. Access to cancer care among Indigenous peoples in Canada: a scoping review. Soc Sci Med 2019;238: 112495.

17. Boyd AD, Song X, Furgal CM. A systematic literature review of cancer communication with indigenous populations in Canada and the United States [published online October 22, 2019]. J Cancer Educ, doi: 10.1007/ s13187-019-01630-2

18. Gifford W, Thomas R, Barton G, et al. Providing culturally safe cancer survivorship care with indigenous communities: study protocol for an integrated knowledge translation study. Pilot Feasibility Stud 2019;5:33.

19. Abdel-Rahman O. Treatment choices and outcomes of non-metastatic hepatocellular carcinoma patients in relationship to neighborhood socioeconomic status: a population-based study. Int J Clin Oncol 2020;25: 861-866.

20. Abdel-Rahman O. Socioeconomic predictors of suicide risk among cancer patients in the United states: a population-based study. Cancer Epidemiol 2019;63:101601

21. Abdel-Rahman $\mathrm{O}$. Impact of $\mathrm{NCl}$ socioeconomic index on the outcomes of nonmetastatic breast cancer patients: analysis of SEER census tractlevel socioeconomic database. Clin Breast Cancer 2019;19:e717-722.

22. Abdel-Rahman O. Prognostic impact of socioeconomic status among patients with malignant melanoma of the skin: a population-based study. J Dermatolog Treat 2020;31:571-575.

23. Siddiqi A, Shahidi FV, Ramraj C, et al. Associations between race, discrimination and risk for chronic disease in a population-based sample from Canada. Soc Sci Med 2017;194:135-141.

24. Toleman MS, Herbert K, McCarthy N, et al. Vaccination of chemotherapy patients-effect of guideline implementation. Support Care Cancer 2016;24:2317-2321.

25. Vollaard A, Schreuder I, Slok-Raijmakers L, et al. Influenza vaccination in adult patients with solid tumours treated with chemotherapy. Eur J Cancer 2017;76:134-143
26. Loulergue $\mathrm{P}, \mathrm{Mir} \mathrm{O}$, Alexandre J, et al. Low influenza vaccination rate among patients receiving chemotherapy for cancer [letter]. Ann Oncol 2008; $19: 1658$

27. Pollyea DA, Brown JM, Horning SJ. Utility of influenza vaccination for oncology patients. J Clin Oncol 2010;28:2481-2490.

28. Friedenreich CM, Pader J, Barberio AM, et al. Estimates of the current and future burden of cancer attributable to sedentary behavior in Canada. Prev Med 2019;122:73-80.

29. Gomez SL, Glaser SL. Misclassification of race/ethnicity in a populationbased cancer registry (United States). Cancer Causes Control 2006;17: 771-781.

30. Lynch BM, Youlden D, Fritschi L, et al. Self-reported information on the diagnosis of colorectal cancer was reliable but not necessarily valid. J Clin Epidemiol 2008;61:498-504.

31. Statistics Canada. Census Profile, 2016 Census. Accessed July 21, 2020. Available at: https://www12.statcan.gc.ca/census-recensement/2016/dp$\mathrm{pd} /$ prof/index.cfm?Lang $=\mathrm{E}$

32. Thomas S, Wannell B. Combining cycles of the Canadian Community Health Survey. Health Rep 2009;20:53-58.

33. Yost K, Perkins C, Cohen R, et al. Socioeconomic status and breast cancer incidence in California for different race/ethnic groups. Cancer Causes Control 2001;12:703-711.

34. Yu M, Tatalovich Z, Gibson JT, et al. Using a composite index of socioeconomic status to investigate health disparities while protecting the confidentiality of cancer registry data. Cancer Causes Control 2014;25: 81-92.

35. Kurtz DLM, Janke R, Vinek J, et al. Health sciences cultural safety education in Australia, Canada, New Zealand, and the United States: a literature review. Int J Med Educ 2018;9:271-285.

36. Blaes $A H$, Adamson PC, Foxhall $L$, et al. Survivorship care plans and the commission on cancer standards: the increasing need for better strategies to improve the outcome for survivors of cancer. JCO Oncol Pract 2020;16:447-450. 


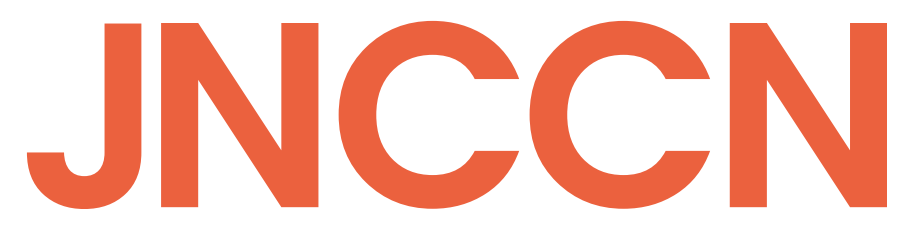
National
Comprehensive
NCCN Cancer
Network $^{\circledast}$

Supplemental online content for:

\section{Racial Background and Health Behaviors Among Adults With Cancer in Canada: Results of a National Survey}

Omar Abdel-Rahman, MD

J Natl Compr Canc Netw, doi: 10.6004/jnccn.2020.7681

eTable 1: Weighted Frequencies of Baseline Characteristics of Included Participants 


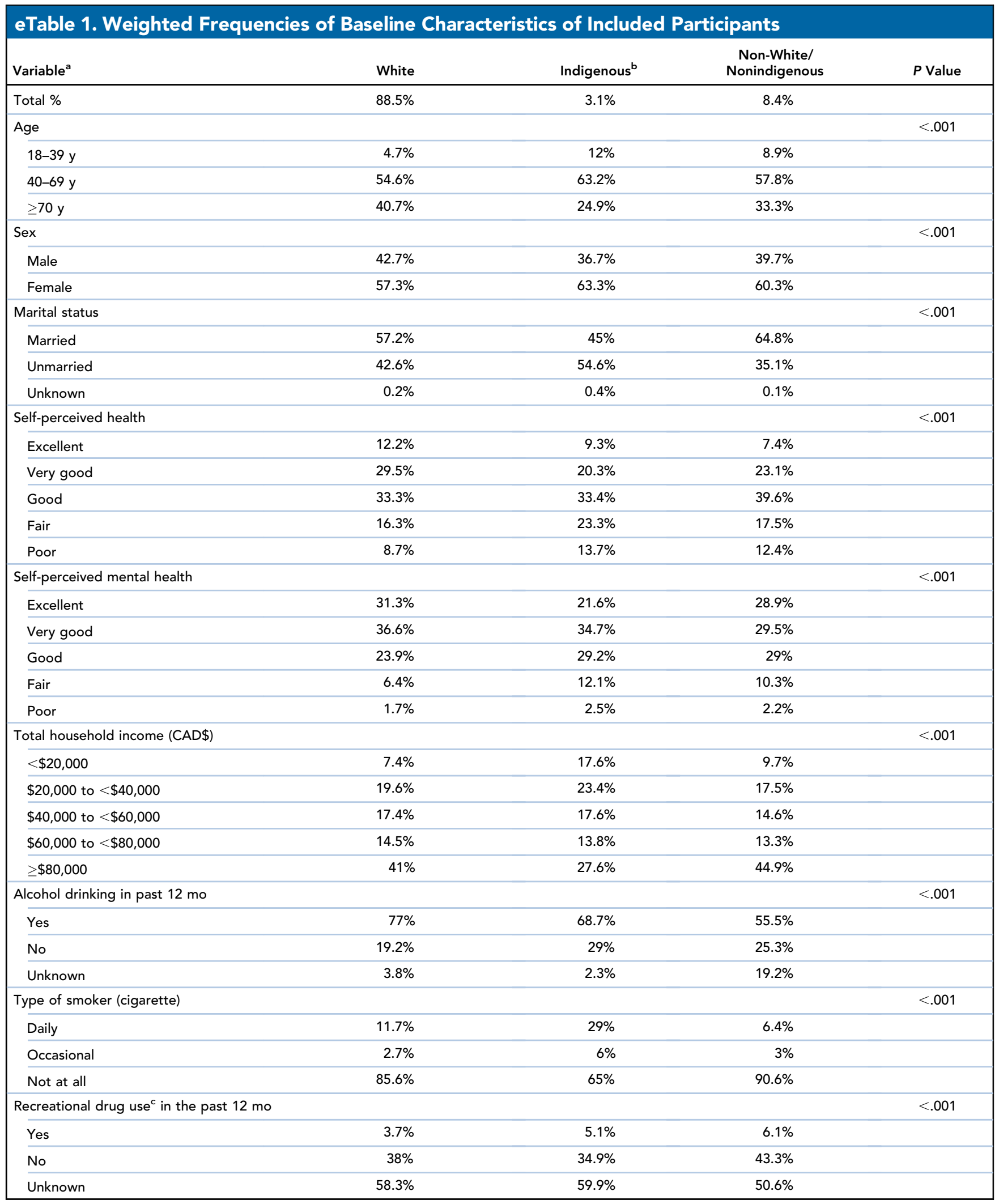




\section{eTable 1. Weighted Frequencies of Baseline Characteristics of Included Participants (cont.)}

\begin{tabular}{|c|c|c|c|c|}
\hline Variable $^{a}$ & White & Indigenous $^{\mathrm{b}}$ & $\begin{array}{c}\text { Non-White/ } \\
\text { Nonindigenous }\end{array}$ & $P$ Value \\
\hline Influenza vaccination & & & & $<.001$ \\
\hline Within $1 \mathrm{y}$ & $54.6 \%$ & $46.7 \%$ & $48.9 \%$ & \\
\hline Not received or received $>1$ y ago & $45.4 \%$ & $53.3 \%$ & $51.1 \%$ & \\
\hline Physical activity (as per CPAG) & & & & $<.001$ \\
\hline At/More than recommended & $47 \%$ & $51.8 \%$ & $43 \%$ & \\
\hline Less than recommended/no exercise & $53 \%$ & $48.2 \%$ & $57 \%$ & \\
\hline Self-reported cancer status ${ }^{d}$ & & & & $<.001$ \\
\hline Current cancer diagnosis & $21.6 \%$ & $17.8 \%$ & $25.5 \%$ & \\
\hline History of cancer & $78.4 \%$ & $82.2 \%$ & $74.5 \%$ & \\
\hline
\end{tabular}

Abbreviation: CPAG, Canadian Physical Activity Guidelines.

${ }^{a}$ Missing data: perceived health, 0.3\%; perceived mental health, $6.5 \%$; total household income, $<0.1 \%$; type of smoker, $0.1 \%$.

${ }^{b}$ Includes the 3 groups described as aboriginal within Canadian Community Health Survey datasets: First Nations, Inuit and Métis.

Including marijuana.

${ }^{d}$ Depends on the type of responses patients provide in the survey. 